\title{
El concepto de carne en la primera teología y el "cuerpo hablante»
}

\author{
The concept of flesh in the first theology \\ and the «speaking body»
}

\author{
Sara Vassallo
}

\section{RESUMEN:}

El texto propone, a condición de contextualizar y releer históricamente el significante carne de la tradición judeo-cristiana, que el «margen más allá de la vida» que Lacan sitúa entre cuerpo y significante en 1960 remite a un lugar análogo al que ocupan tanto semántica como sintácticamente, los significantes latino caro y griego $\sigma \alpha \rho \zeta$, que traducen el hebreo bá-sar (carne). Por retroacción histórica, y dando prevalencia a la letra sobre el sentido, se vería que los primeros textos teológicos sitúan este significante en un lugar de «béance», o por lo menos de contradicción insostenible, donde nada representable ni pensable permite producir una síntesis. Interrumpiendo el dualismo platónico alma/cuerpo, la carne del cristianismo, que no es ni cuerpo ni alma, desorganiza la dualidad, abriendo a un sistema ternario cuerpo/carnelespíritu, referente conceptual que alimenta probablemente la última enseñanza de Lacan y donde la «carne» responde a un Real.

\section{PALABRAS Clave:}

Carne - espíritu - cuerpo - significante verbo

\section{SUMMARY:}

The text proposes, on the condition of contextualizing and re-reading historically the significant flesh of the Judeo-Christian tradition, that the margin "beyond life" that Lacan places between body and signifier in 1960 refers to a place analogous to that occupied by so much semantics as syntactically, the signifiers Latin expensive and Greek $\sigma \alpha \rho \zeta$, which translate the Hebrew ba-sar (flesh). By historical retroaction, and giving precedence to the letter on the sense, it would be seen that the first theological texts place this signifier in a place of "béance", or at least of unsustainable contradiction, where nothing representable or thinkable can produce a synthesis. Interrupting the soul / body platonic dualism, the flesh of Christianity, which is neither body nor soul, disorganizes duality, opening up a ternary body / flesh / spirit system, a conceptual referent that probably feeds Lacan's last teaching and where the «meat» responds to a Real.

\section{WORD PAD:}

Flesh - spirit - body - signifier - word 

Me centraré en los impasses teóricos que plantea la primera teología (san Pablo, Tertuliano, Ireneo de Lyon, Agustín de Hipona) en torno a la noción de carne. Me propongo mostrar que las tríadas cuerpo/ carne/espíritu, cuerpo/carne/alma, cuerpo/ verbo/carne, subyacen a lo que en algunos tramos del discurso de Jacques Lacan se presenta distribuido entre el cuerpo y el significante.

Tratar el tema de la carne en la acepción en que lo utilizó la primera teología supone un telón de fondo muy complejo (semántico, cultural, etimológico, histórico, filosófico), del cual enfocaré solamente unas pocas articulaciones.

En su traducción desde el hebreo basar al griego $\sigma \alpha \rho \xi$, $\sigma \alpha \rho \kappa o ́ \varsigma$ y al latino caro, carnis, la construcción teológica hace del término carne -en la encarnación, en el pecado, la gracia o la voluntad- el lugar de una inconmensurabilidad entre dos instancias opuestas: cuerpo $(\sigma \omega \dot{\mu} \alpha)$ y alma ( $\psi v \chi \eta ́)$, cuerpo y espíritu ( $\pi v \varepsilon v \mu \alpha$, soplo, aire, espíritu). Las dos instancias se ven vinculadas así por una tercera -la carneque no coincide con ninguna de ellas pero que hará predominar, como veremos, a una sobre otra. Esa característica requiere una retórica ternaria que impugne los dualismos sin poder, al mismo tiempo, prescindir de ellos, poniendo en escena el intervalo insalvable que separa ambos términos. Una de sus figuras retóricas, aunque no la única, para expresarlo, es el oxímoron: "cuerpo místico", (De Lubac, 2009), «carne espiritual» (Baudelaire, 2002), «vida muerta» o «muerte viva» (san Agustín, 1964).

San Pablo, judío de la diáspora que escribe en griego, traduce con $\sigma \alpha \rho \zeta$, баркós el bá-sar hebreo: alimento, carne de los animales destinados al sacrifico y también carne humana. En las epístolas a los Gálatas y a los Corintios, carne y espíritu se oponen de un modo irreductible. «La carne y la sangre (basar wa-dam) no pueden heredar el reino de Dios» (Cor I, 15,50), o bien : «El hombre con alma [animal] no recibe las cosas del Espíritu de Dios, que para él son locura» (Cor, I, 2,14) ; o en la dicotomía: "vivir según la carne» (katá sarká) o «vivir según el espíritu» (katà pneuma) (Gálatas). Pero por un proceso semántico que veremos ahora, el término se bifurcará entre dos sentidos: por un lado la debilidad y corrupción humanas connotada en basar wa-dam y por otro lado la carne de la víctima del dios crucificado (Lacoste, 1998: 258 y ss). En virtud de una diseminación y equivocidad semánticas que persistirán en el Nuevo Testamento, se lo leerá en los evangelios (Mateo, 24) como sinónimo de vida o «carne de los vivos» (Mateo, 24), para designar la resurrección de la carne.

Esta alteración semántica produce no solo una modificación del basar hebreo sino que a la vez restablece un vínculo entre el cuerpo y el alma de la dualidad platónica. Como ese vínculo depende de la «voluntad", un tercer término introducido en la dualidad no coincidirá positivamente ni con uno ni con otro, aunque sea forzoso ponerlos en oposición. Al marcar una proporción inconmensurable entre ambos, la falta de un punto común encuentra en el significante carne un vínculo enigmático que abre más bien un agujero entre el cuerpo y el alma. En la primera teología, la «carne» designa en realidad algo que no es ni cuerpo ni espíritu sino que más bien divide el cuerpo, el cual se encuentra 
habitado a partir de allí por algo que no es cuerpo. Una fórmula de San Agustin da cuenta de la dificultad: «La forma en que el alma se vincula con el cuerpo es incomprensible para el hombre, pero ese incomprensible es el hombre mismo» (San Agustín, 1960, Livre XXII -10).

Todo ocurre, entonces, como si carne, sustrayéndose a la dualidad cuerpo/alma, designara un tercero que surge por desliz alterando la oposición sin suprimirla. $\mathrm{Si}$ al interpretar la epístola a los Corintios, san Agustín ve al hombre ya sea como un

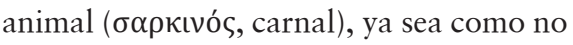

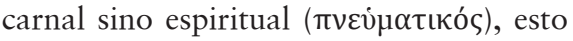
no significa que la dualidad sea originaria ni mucho menos inalterable sino que, como diría Lacan, si hay dos, es porque un tercero los produjo antes de ser dos.

Por un giro que aclara y complejiza a la vez esta lógica triádica, la intromisión del espíritu modifica a su vez el sentido de carne. Porque en cuanto se la opone, junto al alma, al espíritu, la carne se vuelve receptáculo del espíritu: «No es la carne corruptible la que volvió pecadora al alma sino que el alma pecadora volvió corruptible a la carne» (San Agustín, 1960, Livre xiv). La sinécdoque carne/ hombre redunda entonces en una nueva visión de la relación de la voluntad con el pecado: san Agustín exceptúa a la carne como causa de la caída, la causa es la voluntad: «Vivir según la carne es malo, pero la carne no es mala» (San Agustín, 1960, Livre xiv). ${ }^{2}$ La «palabra propia de la encarnación" media así, aunque de un modo oscuro, entre el primero y tercer término. San Agustín lo confirma una vez más en una frase que lleva la marca indeleble de su pensamiento: "Se llama carne lo que la carne no comprende y la carne comprende tanto menos cuanto que se llama carne». ${ }^{2}$ Sin embargo, sin la carne, punto ciego que no comprende y que es él mismo incomprensible, el Espíritu no existiría. Otro pasaje, extraído de un sermón, explica así esa ligazón: «Gracias al Espíritu, la carne es útil, ella, que por sí misma no sirve para nada. Porque es gracias a la carne que el espíritu hizo algo por nuestra salvación. La carne fue el recipiente de que él disponía, mediante ella el espíritu nos ha salvado». La encarnación del Espíritu en el Verbo da cuenta, a costa de pasar por un punto incomprensible, de nuestra posible relación con el Espíritu.

Si la encaramos a través de sus vueltas semánticas y no desde una dualidad somera del bien y del mal, la acepción pecaminosa en que se inscribe la carne en la teología cristiana primitiva (siglos II-V d. C), vinculada con lo "putrescible" en el mito de la caída, cambia de carácter. En los textos fundadores, en efecto, carne se yuxtapone con cuerpo, en una relación deslizante entre uno y otro, y hasta puede ser omitido. Sin ir más lejos, san Pablo en Cor I, 15, 42-44: "Así ocurre con la resurrección de los muertos. El cuerpo nace corruptible: resucita incorruptible; nace despreciable y resucita glorioso [...]

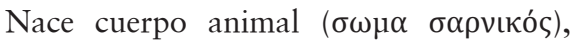
resucita como cuerpo espiritual $(\sigma \omega \mu \alpha$ $\pi v \varepsilon \dot{u} \mu \alpha \tau$ «ós). Hay un cuerpo animal, pero hay también un cuerpo "espiritual». O también: «Ese cuerpo [glorioso] será idéntico a sí mismo, entero pero transformado a la manera del cuerpo de Cristo» (Cor I, 15). O en la epístola a los Filipenses $(3,21)$ : «El Señor transformará el cuerpo de nuestra humillación volviéndolo semejante al cuerpo de su gloria...». El paso de la humillación a la gloria, de lo corruptible a lo incorruptible, exige la presencia del significante $\sigma \alpha \rho \zeta$ (y 
no $\sigma \omega \mu \alpha)$, aunque ese significante esté ausente.

Es la expresión «voluntad carnal» en un pasaje de las Confesiones (san Agustín, 1964, Libro VIII, 5) que glosa la epístola a los Galatas (5, 16-17), la que nos da la clave del problema: "Dos voluntades luchaban en mí, la vieja y la nueva, la primera carnal, la segunda espiritual». Carne y voluntad confluyen. El paso de una voluntad a otra $-\mathrm{y}$ de un cuerpo a otro- implica en silencio el concepto de carne. A condición de conservar su «incomprensibilidad», que se vuelve legible en los pasajes de la Ciudad de Dios en que san Agustín, lector de Cicerón, aludiendo a las morales epicúrea y estoica, dice que los epicúreos (para quienes el Bien es el placer) y los estoicos (para quienes el Bien es la virtud), "ambos son carnales». El mismo razonamiento le hará decir en otro lado que "las virtudes paganas son vicios brillantes». Notemos -y no es inofensivo para nuestro propósito- que Agustín de Hipona no resuelve el problema con una especulación conceptual sino con un quiasmo: «Exaltar la naturaleza del alma como el soberano bien y condenar como un mal la naturaleza de la carne, es codiciar carnalmente el alma y huir carnalmente de la carne. Ello es así porque nos inspiramos de la vanidad humana y no de la verdad divina» (san Agustín, 1960, XIV, 4-5).

\section{II}

Convenimos en que la contextualización histórico-social imbricada en estos procesos semánticos es imprescindible. Por razones de espacio, no podemos entrar en el tratamiento histórico de la práctica de la abstinencia sexual como expresión de la incriminación de la carne. El análisis ha sido hecho, entre otros, por Peter Brown y por Michel Foucault. Este último propone una lectura que prescinde de toda explicación que tenga que ver con alguna «represión sexual» sino que piensa el discurso teológico sobre la carne como una "puesta en discurso" de la sexualidad desde la espiritualidad monástica. Sea cual fuere la perplejidad que pueda provocarnos el fenómeno de la abstinencia sexual como valor social y la impugnación, desde el siglo II, de la sexualidad por la Iglesia cristiana, lo que queremos poner de relieve es que esa impugnación no deja de afirmar, por la negativa, que la condición humana está marcada por el deseo sexual, definiendo al hombre por la carne.

Michel de Certeau, uno de los discípulos que llevaron más lejos las consecuencias de la reflexión de Lacan en el campo religioso, profundizó con particular elocuencia este punto: "El ascetismo no es rechazo puro y simple del cuerpo, sino una etapa preliminar para ofrecer el cuerpo al espíritu. Etapa para recobrar el cuerpo [...] Los que se toman en serio la palabras de Cristo: Hoc est enim corpus meum (éste es mi cuerpo), son aquellos a quienes les duele la ausencia de cuerpo. El cuerpo, para ser cuerpo, debe pasar por alguna experiencia de falta». Y no se privará de decir que el cristianismo «se instituyó por la pérdida de un cuerpo... desaparición fundadora». (M. de Certeau, 1982: 108).

La complejidad empieza, en efecto, cuando los textos indican que la desvalorización encierra una función dada a la carne que la pone en un lugar clave para comprender a la vez la caída y la redención. O sea, la cuestión de cómo 
un tercer término desorganiza y hace deslizarse el sentido de los otros dos, cómo $\sigma \alpha \rho \zeta$ cambia el sentido de $\pi v \varepsilon \dot{v} \mu \alpha$ y $\psi u \chi \underline{n}$ y cómo caro en san Agustín, leyendo a Cicerón, hace deslizarse el sentido de corpus y anima disolviendo la dualidad, todo ello no deja de anticipar la extraña y nueva acepción que tomó el término jouissance en psicoanálisis por obra de Lacan, con la contradicción imposible de eliminar -entre cuerpo y significante- que ella implica.

Tertuliano (160-220 d.C), que influyó fuertemente en san Agustín, es uno de los representantes más típicos de esta contradicción, que es al mismo tiempo una rehabilitación paradójica de la carne. Muy inspirado por el pensamiento estoico materialista, reaccionó contra el desprecio por la carne (de Marción y Valentino) y junto con Ireneo de Lyon, combatió la desvalorización de una «carne» que aquellos -junto con gnósticos y maniqueos- excluían de la salvación. Así, la verdadera encarnación del Hijo (tan perfecta que excluye la virginidad de María in partum et post partum) se vuelve garantía de la resurrección y concierne en forma directa la elaboración trinitaria, donde la segunda persona del Hijo no excluye su eternidad (idea decisiva para san Agustín): «Es en la carne, con la carne y por ella, que el alma medita todo lo que medita su corazón» (Tertuliano, 2010).

Lo importante para Tertuliano es oponerse al dualismo gnóstico, rehabilitando para ello el nudo inextricable que une cuerpo y alma, lo cual acarrea una solidaridad fundamental de ambos en la caída, el pecado y la responsabilidad, en la salvación, el juicio final y la recompensa. En De la resurrección de los muertos y en su tratado Acerca del alma afirma que «el alma es corporal» (Tertuliano 1980; Tertuliano 2001). En el trabajo practicado al mismo tiempo sobre la Biblia hebrea y los textos clásicos griegos y latinos, sobre todo Platón y Plotino, todo ocurre, a nivel semántico, como si caro y spiritus desequilibraran la dupla corpus/anima. En el mismo texto sobre La resurrección de los muertos: «El alma no está nunca aislada de la carne, mientras esté en la carne, no hay nada que no haga sin ella...» (Tertuliano, 1980). Sobre todo, se opone a las interpretaciones cristianas que retoman las ideas neoplatónicas, omnipresentes, según las cuales la resurrección se opera a partir de la liberación del alma del «sepulcro» o "cárcel» del cuerpo (aunque esta idea estaba, aunque de otro modo, en san Pablo, para quien el alma "se escapa del siglo» porque éste es la morada de los muertos, o sea, de los que ignoran a Dios). "Ya sea en el cerebro -escribe- o entre las dos cejas, o en cualquier lugar que hayan decidido los filósofos ubicar el santuario en que nacen nuestras ideas, lo que se llama hegemonikón [facultad que dirige el alma] es la carne la única sede de los pensamientos del alma [...] Hélos ahí enumerando las faltas de la carne: pecadora, y por lo tanto merecedora de suplicios. Nosotros, en cambio, ponemos de relieve las virtudes de la carne. Por obras buenas, ella recibirá también recompensas [...] Y aunque sea cierto que es el alma la que lleva a toda acción, la ejecución es el hecho de la carne». (Tertuliano, 1980 ; J. Alexandre, 2001).

Otro punto clave es la discusión entablada por Tertuliano acerca del juicio final, cuando en el cap. XVII de Resurrección de los muertos ataca a «los adherentes menos sutiles a nuestra opinión [que] pensarán que la carne debe presentarse ante el 
juicio final porque el alma no podría experimentar sufrimientos ni deleite si fuera incorpórea» (Tertuliano, 1980). O sea, le conceden que el alma debe ser corpórea nada más que porque sin cuerpo no se sufre en el infierno. Eso no basta, le replica a Marción, el alma necesita al cuerpo (transformado ya de cuerpo puramente biológico en carne) «no porque no podría sentir nada sin ella sino porque debe sentir al mismo tiempo que la carne» (Tertuliano, 1990-2004; 2010).

Puede parecer difícil conciliar esta reivindicación con pasajes donde la carne, emparentada con el cuerpo, da lugar, siempre en la disputa con Marción y esta vez respecto de la virginidad de María, a la pregunta: «¿Cómo el cuerpo del dios podría nacer de las entrañas sanguinolentas manipuladas por las parteras y los médicos?» (Tertuliano, 1990-2004: 32). O cuando en Sobre los ayunos presenta el cuerpo «obstruido y constipado de alimentos, inundado de vino, con sus excrementos ardiendo y cocinándose, se vuelve una letrina que puede preparar a la lascivia». Sin embargo, sería un error considerarlo como una contradicción, no solo porque la novedad de estos textos se debe a que la verdad no se vehicula en ellos a través del principio aristotélico de no-contradicción sino porque, aunque sea cierto que alma y cuerpo están separados, si es preciso comparecer ante el juicio eterno con su carne, es porque el cuerpo no basta. La función de la carne ligada a la voluntad resuelve el problema en el párrafo 7 de La resurreción de los muertos: «Como los actos están ligados por su lado a los méritos, y como esos actos se cumplen por intermedio de la carne, no basta que el alma sea recompensada o atormentada sin la carne, aunque posea un cuerpo y miembros que no le bastan para sentir completamente ni para actuar perfectamente» (Tertuliano, 1980). Dios (y Tertuliano), pues, juzgan al hombre como alma y cuerpo unidos $-\mathrm{y}$ a la vez separados- por la carne.

Noto al pasar que la diferencia entre cuerpo y carne (corpus y caro, $\sigma \omega \mu \alpha$ y $\sigma \alpha \rho \zeta)$ responde en sordina a la misma lógica paradójica que opone la fe y las obras en la epístola de san Pablo a los colosenses -donde la fe necesita, no obstante, de las obras- y resulta coherente con los ataques contra la Torah: «¿Por qué se os imponen estos preceptos? ¡No pruebes! ¡No toques!, preceptos que se vuelven perniciosos por el abuso y que solo se fundan en las doctrinas e imperativos de los hombres. Tienen una apariencia de sabiduría ya que indican un culto voluntario, humildad, desprecio del cuerpo, pero su sabiduría es aparente, no tienen ningún mérito y contribuyen a satisfacer a la carne» (Col, 2, 21-23). Se ve la paradoja: observar minuciosamente las prescripciones del Levítico, que afectan y mortifican el cuerpo, redunda en una satisfacción de la carne (ambición, vanidad, ser el más meritorio). Por donde se ve que cuerpo y carne están lejos de ser la misma cosa.

Tertuliano plantea entonces una contradicción interna a la noción de carne, ya que, a partir del momento en que se la presenta como la sede de la voluntad, en ella reside tanto el origen de las buenas obras como de las malas. Como diría Baudelaire, la carne se vuelve el lugar de una «doble postulación». 
La retórica ternaria de la que hablábamos al comienzo, donde un tercer término no siempre es nombrado, se reitera a través de este tipo de enunciados:

Es en la carne, con la carne y por ella, que el alma medita todo lo que medita su corazón. (Tertuliano, 1980).

Se llama carne (caro) lo que la carne no comprende [donde el significante omitido es spiritus] y la carne comprende tanto menos cuanto que se llama carne. (san Agustín, véase nota 3).

Vivir según la carne es un mal aunque la carne no sea un mal. (san Agustín, 1960: libro XIV).

No es la ley de la ciudad terrestre la que va a hacer vivir a la ciudad terrestre, así como la Iglesia cristiana tampoco va a hacer vivir a la Iglesia cristiana sino un principio superior a ella. (san Agustín, 1960: libro XV).

Todo lo que es un mal no se vuelve forzosamente bien, pero nada puede volverse bueno si antes no fue malo. (san Agustín, 1960: libro xv, 1).

Así como la voluntad no va a hacer vivir a la voluntad, del mismo modo no es la voluntad de Dios la que va a poder realizarse en el hombre si éste no la reactiva por su propia voluntad. (san Agustín, I98I).

Así como la ley no hace vivir a la ley sin la caridad, asi también la caridad no hará vivir a la caridad sin la ley. (san Agustín, I98I).

En resumen, dos términos inconmensurables entre sí (carnelespíritu, ley/ca- ridad, ciudad terrestre/Iglesia cristiana, obras/fe, voluntad humanalvoluntad divina) se atan a la vez por un significante que, omitido o no, los vincula en una desproporción radical.

\section{IV}

Nos topamos aquí con una dificultad. Los textos que hemos considerado dicen dos cosas a la vez : 1) Por un lado, pese a la confluencia entre dos registros incompatibles, la carne por la que caemos y la carne por la que nos salvamos es la misma. 2) Por otro lado, según que reciban o no el Espíritu, no son idénticas. ¿Cómo dar cuenta de esta contradicción?

Es aquí donde entra en función la idea de encarnación, a condición de recordar, con san Agustín, que en ella, el Hijo devenido Verbo no piensa a Dios sino que lo encarna por el verbo: «El Hijo de Dios no es llamado [en el evangelio de san Juan] pensamiento de Dios [cogitatio Dei] sino Verbo de Dios [verbum Dei]» (san Agustín, 1948, Libro xv).

De este modo, «el Verbo se hizo carne» no quiere decir que el Verbo sea igual a la carne (que es solo humana): queda una diferencia interna a la encarnación, que responde asimismo a la imposibilidad, como reza la frase citada de san Agustín, de pensar (cogitare) al Padre como concepto.

La idea de encarnación, como se sabe, es el pasaje obligado para entender el paso -y la ruptura- del platonismo al cristianismo (Gilson, 1999).

En la doctrina, la fuente principal es en este punto el prólogo del $4^{\circ}$ evangelio de san Juan, donde se dice en una única ocurrencia, nunca reiterada después: «El 
verbo se hizo carne (ho logos sarz egéneto) y habitó entre nosotros». Verbum caro factum est.

Notemos que el Verbo se hizo carne y no cuerpo. Retomando el texto de san Juan, que reconoce a Cristo «venido en la carne», san Pablo dice en la epístola a los Romanos: «Dios condenó al hombre en la carne enviando, a causa del pecado, a su propio Hijo en una carne semejante a la del pecado» (vIII, 3).

Habrá que detenerse en esta paradoja, esto es: para liberarnos del pecado y la muerte vinculados con la carne, Dios nos envió a su Hijo, «encarnado». Las innumerables discusiones derivadas de allí giraron en torno a la reunión en Cristo, mal llamado mediador, de dos instancias, divina y humana, cuya diferencia sería inconciliable para el entendimiento. Si es a la vez los dos, o sea, hombre y dios, ¿cómo se relacionan los dos registros? Si se pone a uno de los términos en cupla con el otro como si se tratara de un par homogéneo -aun cuando sean contrarios- lo divino se hace humano (herejía de Arrio). En cambio, para desparejar a los dos términos de la cupla, es lo divino lo que tiene que actuar como tercero. El problema no es ajeno al nudo borromeo de Lacan, más aún, constituye su modelo ancestral: dos términos solos no pueden entrar en relación si un Tercero (como Otro) no los ata. No toda estructura ternaria es borromea pero la estructura ternaria es borromea cuando se plantea la necesidad de que un tercer elemento, heterogéneo a los otros dos, los anude. Como dice Lacan, no es el dos el que constituye el tres sino al revés. «Porque cuanto más avanzo, más me convenzo que solo contamos hasta tres. $\mathrm{Y}$ aunque solo porque contamos hasta tres podemos llegar a contar dos...otra vez la verdadera religión...» (Lacan, 1973-1974, 11/12/73). La búsqueda de un Tres corresponde, al comienzo del seminario xxI, a lo Real: «Si añado lo Real a los otros dos, es solo para que dé tres $[. .$.$] justamente$ los tomo desde este ángulo de que son tres, tres e igualmente consistentes. Es una primera manera de abordar qué es de este Real» (Lacan, 1973-1974).

Vuelvo al pasaje problemático de san Pablo (Rom, VIII-3): «Dios condenó al pecado en la carne enviando, a causa del pecado, a su propio Hijo en una carne semejante a la del pecado». Como tanto insistió Ireneo de Lyon, el que debía matar al pecado se convierte en eso mismo en que consistía el pecado, es decir, en el hombre retenido en la esclavitud por el pecado y el poder de la muerte, para que el hombre saliera de la muerte (Irénée de Lyon, 1969).

Michel Henry lo resume así: «el lugar de la salvación es también el lugar del pecado, es decir, nuestra carne finita y putrescible» (Henry, 1987). Sin embargo, la doctrina dice que, si para salvar al hombre de la carne, el redentor tuvo que revestir la carne o el aspecto humano, no por ello se vuelve enteramente de la misma estofa que el hombre-carne. La carne de Cristo no es la carne humana (es el tema de Tertuliano en De corpus Christi), y como anota Michel Henry, la carne «no podía venir sino del Verbo" (Henry, 1987: 367). Y si es cierto, como sostiene M. Henry en el mismo libro, que «es por la carne que el Verbo se hizo hombre» (Henry, 1987: 12), el Verbo no le debe nada a la carne. Si Cristo pudo encarnarse "gracias a la carne", es el verbo el que usa a la carne pero no la carne al verbo. Por eso puede decir el mismo autor que es la carne, y no el 
cuerpo, la que goza (y por tanto, también la que se angustia).

La relación de exclusión entre carne y verbo se efectúa entonces en detrimento de la carne, aunque para ello haga falta, al mismo tiempo, que el verbo pueda incluirla. Se introduce aquí por lo tanto, paralelamente, un intervalo infranqueable (entre carne y verbo) que reitera en otro nivel el que separa lo humano y lo divino; intervalo solo concebible aceptando que una relación de desproporción o desajuste radicales deba toda su fuerza a la irrupción de un tercero que no homogeneiza sino que produce heterogeneidad.

El plus está del lado del Verbo porque el Verbo es consustancial (omóiesos) al Padre, dice el dogma trinitario, o sea, es eterno, existía antes de la carne. El dogma definitivo se estableció en parte contra la herejía de Arrio, que sostenía que Jesucristo era un hombre histórico y mortal, «no había nada antes del Verbo», decía Arrio, el Padre y el Hijo pertenecían por lo tanto a dos sustancias distintas. (Se comprende a partir de ahí la homonimia de Lacan: RSI/hérésie). Ya sea que se adhiera a Arrio, a los gnósticos (dualismo), a los maniqueos o a los adherentes de Sabelius (subordinacionismo), estamos en la herejía, no hay tríada ni nudo posible. No hay Tres.

Etienne Gilson siguió la misma lógica cuando observa que «si Dios creó al hombre en el tiempo, se encarnó para redimirlo del tiempo [...]»(Gilson, 1999). No se puede decir mejor la paradoja que subyace a la idea de encarnación de lo divino en lo humano.

Reconocemos también esta lógica en la carta $\mathrm{n}^{\circ} 5$ en que Abelardo responde a Eloísa (siglo XI) a quien se dirige diciéndole: «en otro tiempo mi mujer en la carne, ahora mi hermana en el espíritu». El texto de Abelardo vehicula la misma ubicación intersticial de la carne como punto en que confluyen las buenas obras y las malas, la salvación y la condena. Reproduce el contenido doctrinal: aquello por lo cual caímos (la carne) es etiam [también] aquello que nos salvará. Lo que los une -le escribe a una Eloísa que ve en ello una cobertura mentirosa y puramente intelectual- es la separación carnal, más aún, que Dios los bendijo al separarlos pero, para que esa bendición se produzca, fue necesario haber pasado por la carne. Es cierto que en el contexto, el argumento es cobarde y utilizado por oportunismo. Eloísa tenía razón, ya que habría que haber deseado la renuncia a la carne -cosa que no fue el caso de Abelardo- para que ésta se volviera válida. La plegaria que le escribe Abelardo para consolarla suena a pretexto. Pero refleja una idea clave de la doctrina: "Castiga a la carne para conservar las almas. Pónnos a prueba, Señor, y tiéntanos, así como el propio profeta lo reclama para decir: examinad primero vuestras fuerzas y luego moderad según ellas el fardo de las tentaciones. Es lo que Pablo pide a sus fieles cuando les dice que 'Dios no los pondrá a prueba más allá de sus fuerzas y que al revés, aumentará sus fuerzas con la tentación'». (Abelard-Héloïse, 1938: 166).

Toda la dificultad está en que el Verbo, como dice M. Henry, destruye nuestra carne finita muriendo él mismo. Al morir carnalmente, nos hace vivir espiritualmente. Para explicar lo inexplicable, se dice que en él coexisten lo divino y lo humano, lo infinito y lo finito, lo incorruptible y lo corruptible. Es decir, Cristo, como decía Kierkegaard, es un "signo de contradicción» (Kierkegaard, 2011: 307) no 
revocable por ninguna mediación, y ello se debe a una diferencia insalvable (el salto, la «diferencia absoluta») entre lo divino y lo humano, el Verbo y la carne, que ninguna lógica puede esclarecer.

El Verbo, eterno e incorruptible, introduce, como decíamos, una división en la carne finita y corrupta sin anularla como tal. La carne sigue siendo finita y corrupta.

La encarnación implica, pues, un fracaso de lo simbólico, como lo mostraba el pasaje ya mencionado de De Trinitate en xv, 15 en que san Agustín dice que el Padre, encerrado en sí mismo, lugar silencioso de donde no sale palabra alguna, se encarnó en la palabra. Pero esa Palabra (el Hijo) no llega a representar al Padre, no es una cogitatio, es decir, no es del orden del pensamiento: "El Hijo de Dios no es llamado [en las escrituras, o sea, en san Juan] pensamiento de Dios [cogitatio Dei] sino Verbo de Dios [verbum Dei]» (san Agustín, 1948: Libro xv).

\section{V}

Sería difícil negar que el intervalo que dista entre el hombre carnal y el espiritual, resuelto en los textos que hemos recorrido por una inoculación de «sentido religioso» dado a la carne, no sea el referente histórico-conceptual sobre el cual se elabora, por cierto de un modo oblicuo y tal vez ignorado (teniendo en cuenta, además, los profundos cambios acarreados por las sucesivas lecturas de los textos bíblicos), el tema lacaniano del «logos literal» que atraviesa el cuerpo en la conferencia Freud en el siglo (Lacan, 1981: 275). El «cuerpo hablante» de la última etapa de la enseñanza de Lacan prolonga la misma idea.
Habíamos dicho que el vínculo triádico que se sustituye a la dualidad platónica abría un agujero entre el cuerpo y el alma, no sin conservar esa dualidad. Y que por marcar una relación inconmensurable entre sus términos, encontraba en el significante carne un vínculo que sigue siendo enigmático, en tanto sede de la contradicción insoluble entre lo humano y lo Otro de lo humano (notemos que en el Lacan que sigue a Lévi-Strauss, lo Otro de lo humano es lo Simbólico, que no tiene ningún sentido "humano»).

Se nos hizo muy visible que aquello que conserva un enigma de sentido, o sea, el Verbo hecho carne, implica a su vez una laguna. Ya que ninguna explicación «natural » o racional da cuenta de la diferencia que queda entre verbum y caro.

Así como el falo "obstaculiza» y al mismo tiempo permite la «relación entre sexuados» (Lacan, 1974-1975), así también el Hijo de Dios une y al mismo tiempo mantiene separadas a la carne divina con la humana. Está el Verbo entre ambos.

En realidad, carne designa algo que no es ni cuerpo ni espíritu, sino que más bien divide al cuerpo. Paradójicamente, el cuerpo se encuentra habitado a partir de allí, es decir, a partir de la intromisión de algo diferente de él, por algo que no es cuerpo. Leído desde este ángulo, el siguiente pasaje de Subversión del sujeto y dialéctica del deseo, donde el significante irrumpe en el «cuerpo vivo" (el cuerpo de la biología), hace entrever un proceso similar:

Reconozcan en la metáfora del retorno a lo inanimado con que Freud afecta a todo cuerpo vivo, ese margen más allá de la vida al ser que el lenguaje asegura al ser por el hecho de que habla, y que es nada más 
que el margen en que ese ser compromete (engage) en posición de significante no solamente lo que en su cuerpo se presta a ser intercambiable, sino ese cuerpo mismo. (Lacan, Écrits: 162)

El margen «más allá de la vida» entre cuerpo y significante remite a un lugar que podría ocupar, en la sintaxis de Lacan y por retroacción retrospectiva, el concepto teológico de carne, como significante dividido que a su vez divide.

Se trata, como es obvio, de un lugar de «béance» donde no hay nada representable ni pensable: lo Real mismo.

Si a través de la encarnación del Verbo, la teología pensaba algo del orden de la relación del cuerpo con lo que él no es, el pasaje de Subversión dice que el cuerpo vivo (el de la ciencia médica) está sometido al significante, en el que está alienado. No puede sobrevolarlo ni pensarlo como concepto, por eso «engage» en posición de significante su cuerpo mismo, donde «engage» es casi equivalente de «encarna» (reencontramos aquí la diferencia agustiniana entre cogitare y encarnar por el verbo).

El cuerpo se hace significante y el significante se vuelve de algún modo corpóreo. Si entre ambos hay un "margen», el cuerpo habla gracias al margen (o «béance») entre la vida biológica y ese logos literal introducido como una cuña en un cuerpo que no lo reclamó.

Y dado que el cuerpo resucitado de san Pablo no es ya el alma de Platón, que necesitaba separarse del cuerpo para existir por sí misma, Lacan podría muy bien estar prolongando desde muy otra perspectiva, y probablemente simplemente invirtiendo desde el punto de vista del sentido, el tema paulino y agustiniano de la carne en el Seminario XIX (O peor...):

"Para gozar hace falta un cuerpo, incluso aquellos que prometen beatitudes eternas, no pueden hacerlo sin que el cuerpo se vehicule en ellas. Glorioso o no, debe estar ahí [doit être là]. Hace falta un cuerpo. ¿Por qué? Porque la dimensión del goce del cuerpo es la dimensión por donde se desciende hacia la muerte. Es en ese punto, precisamente, donde el principio del placer en Freud anuncia que sabía muy bien lo que decía, porque si lo leen verán que el placer no tiene nada que ver con el hedonismo, aunque nos haya sido legado por la más antigua tradición. Es en verdad, el principio de displacer... (Lacan, 1972-1973).

Allí donde los textos teológicos hacen entrever una plenitud, ésta se reencuentra en Lacan en forma de «descenso hacia la muerte». La pregunta es: ¿suprimir el sentido religioso equivale a cambiar la estructura?

Parecería que no, ya que, siguiendo la cita anterior, el cuerpo del hedonismo, o el cuerpo del placer, difiere del cuerpo investido por el significante. Vimos, de un modo similar, que la carne de los teólogos nacía semánticamente de una división interna al cuerpo inducida por un registro ajeno a éste. El cuerpo ni siquiera podría ser designado como cuerpo si no fuera nada más que cuerpo. Lugar de una división en sí misma invisible, que no representa al cuerpo, la carne no es solo un concepto moral. Su lugar intersticial e invisible, que necesita el cuerpo para decirse pero que no es el cuerpo, es lo que nos era indicado en el pasaje de san Agustín: "La forma en que el alma se relaciona con el cuerpo es incomprensible para el hombre, 
pero ese incomprensible es el hombre mismo». (San Agustín (1960), xxII-10).

Es obvio que para el psicoanálisis, a diferencia de la «verdadera religión», ningún pneuma tiende un puente entre cuerpo y significante. Muy por el contrario, esa relación exige una «béance» imposible de franquear. Sin embargo, situar el pneuma entre cuerpo y alma para saldar lo que para un espíritu científico y agnóstico sería una distancia insalvable, no contradice, paradójicamente, el hecho de que entre cuerpo y significante haya un agujero. Éste no remite, por cierto, al «camino, la Verdad y la Vida» ni al «soplo» y «espíritu de vida», fuente de donde surgen la unidad y el amor. Sin embargo, lo que se pierde en el plano del sentido religioso no elimina la estructura triádica: cuerpo/Real/significante. Es imposible no poner algún significante en el agujero de lo Real (la prueba es que en RSI, Lacan hace surgir a Dios como Simbólico «vuelto a escupir» por lo Real).

«Por cierto, la letra mata, se dice, mientras que el espíritu vivifica -recuerda Lacan en La instancia de la letra- [....] pero también nos preguntamos cómo, sin la letra, el espíritu viviría» (Lacan, 1966: 267) ¿Pero quién puede dar el salto desde la letra hacia lo que ella significa» (a lo «legible» o «significable», eso que el estoico Crisipo llamó lektón) sin pasar por el sentido? De ahí que Lacan no pueda privarse de vincular goce y sentido a través del neologismo «jouis-sens» en homonimia con jouissance.

Queda un hiato entre el espíritu y la letra. Lo que sabemos por la letra, lo sabemos a condición de que haya un corte con el espíritu.

La paradoja persiste. Es imposible no encontrarla en numerosos contextos de Lacan, por ejemplo: «el yo del enunciado designa al sujeto de la enunciación pero no lo significa».

Queda un abismo entre el Hijo y el Padre (que surge de la diferencia entre pensar y encarnar). De donde se infiere asimismo el abismo entre el verbo y la carne, aunque no se excluyan uno del otro ya que es gracias a la carne, como dice Tertuliano, que la redención es posible y con ella compareceremos en el juicio final.

Hay que mantener entonces dos enunciados a la vez: en virtud de la aparente contradicción por la cual «vivir según la carne es un mal pero la carne no es un mal», la carne participa de dos registros inconmensurables. Se podrá postular, entonces, que aunque sea cierto que el Verbo y la carne no estén en el mismo nivel -uno divino y otro humano- sin la carne, el Verbo no habría podido advenir. Por lo tanto, "comprendiendo incomprensiblemente", como decía Nicolás de Cusa, la carne participa de lo divino.

En este dispositivo trinitario, uno de los tres términos se escabulle pero no por eso hay que identificarlo o yuxtaponerlo con el primero y segundo, es preciso conservarlo como tercero aunque permanezca callado o invisible.

Es así que cada vez que en la primera teología se habla de cuerpo, se tiene que recurrir a otra cosa que no sea el cuerpo para poder decir algo sobre el cuerpo. Se recurre entonces al concepto de carne. Y a su vez, cuando se llega a la carne, se recurre, para diferenciarlo del cuerpo, al concepto de Verbo.

No es imposible que se aloje allí, disimulando sus orígenes, la tríada R/S/I.

Lo cual ocurre en muchos otros autores del siglo xx. No importa que se declaren ateos. El significante, inmortal, deja una marca en la carne mortal y putrescible. Es 
posible entonces que por intermedio de las palabras, la literatura dé muerte al hombre dándole a la vez una vida "segunda»: «El azar me había hecho hombre -escribe Sartre- la generosidad me haría libro. Podría entonces moldear mi conciencia en caracteres de bronce, remplazar los ruidos de mi vida por inscripciones imborrables, mi carne por un estilo, las blandas espirales del tiempo por la eternidad, aparecer ante el Espíritu Santo como un precipitado de lenguaje [...] escribiría para tallar ese cuerpo de gloria en las palabras [...]» (Sartre, 1964: 160-161). Dos veces muerto, vive por la literatura. El proceso se asemeja al de una resurrección: morir a la vida y por esa muerte, vivir una segunda vez como sujeto renacido. Se podrían mencionar otros contextos que prueban lo mismo: cuando en El Ser y la Nada Sartre define la carne (chair), fuera de toda connotación teológico-moral, como «contingencia pura de la presencia» o como «facticidad» ¿por qué la carne así definida necesita ser salvada en su facticidad y contingencia por algo que ella no es? Es ahí donde en el texto irrumpe, en un contexto privado de "sentido religioso", la noción de gracia asimilada a la libertad.

De este modo, la retórica de la primera teología pone en juego la presencia/ausencia de un sujeto capturado en un Real que se burla del principio de no-contradicción, y que hace leer un mismo significante, el de carne, a caballo entre dos registros heterogéneos: Real y Simbólico.

Intenté decir que la reconstrucción retrospectiva permite reconocer en los antiguos significantes caro y $\sigma \alpha \rho \zeta$, el lugar que Lacan terminaría por reservar a lo Real, entre cuerpo (I) y verbo (S), lugar donde no se produce ninguna síntesis (razón que explica quizá que la encarnación del Ver- bo haya sido investida por la categoría de «misterio» con que lo calificaron los padres de la Iglesia). Es allí donde la «libra de carne» cumple su función de resto en lo Real.

\section{Notas}

1. Recalco la extrema equivocidad del término, persistente en la lengua y literatura modernas, con matices propios en cada lengua. En castellano es difícil traducir el verso de Mallarmé: "La chair est triste, hélas ! et j’ai lu tous les livres». En español tenemos un solo término para designar la doble significación dada en los dos vocablos chair/viande (donde la viande designa la carne del animal muerto que se vende en la carnicería, mientras que chair se liga con la carne del ser vivo y también con la desnudez, la vergüenza, la sensualidad, el deseo sexual). La equivocidad del término será elevada por Merleau-Ponty a categoría filosófica al designar con la "chair" la palabra clave con que la filosofía «de ahora en adelante habrá de nombrar la relación del sujeto con el objeto ", la "carne" del mundo anterior a toda relación conceptual y tranquilizadora entre la conciencia que cree conocer aquello que ella no es (Lo visible y lo invisible).

2. San Agustín elabora la sinécdoque hombre con almalhombre espiritual deteniéndose en un pasaje de la epístola I de san Pablo a los Corintios, 3, 11-16 donde баркıvós (carnal) no

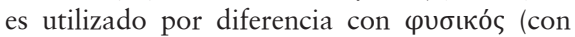
alma) sino más bien en su remplazo. Se trata de la frase «Pero el hombre con alma no recibe las cosas del Espíritu de Dios, que para él son locura" (Ep. Cor, I, 2,14). Agustín concluye: "Ya sea el alma, ya sea la carne, o sea, las dos partes del hombre, pueden designar a éste en su integridad. Así, el hombre dotado de alma y 
el hombre carnal no son dos hombres distintos sino que uno y otro designan al mismo hombre, el que 'vive según la carne'»(Cité de Dieu, XIV,

3. Sociólogo e historiador inglés, trató en su libro Body and society el tema de la renuncia a la carne en el cristianismo primitivo (versión francesa: Le renoncement à la chair. Virginité, célibat et continence dans le christianisme primitif, Gallimard, Paris, 1988). Pasando revista a la práctica de la castración sexual efectiva y su diferencia con la circuncisión, examina cómo el valor moral socialmente sancionado de la abstinencia adviene cuando la disminución de las persecuciones (y del martirologio) hace que la valentía y resistencia del creyente se prueben de otro modo: el cuerpo que resistía a la tortura y al dolor de ser devorado por los animales en los juegos romanos, es remplazado, con el tiempo, por el cuerpo que resiste a la sexualidad. La continencia sexual se volvería así el signo principal del cristianismo primitivo. Tomando en cuenta el problema del milenarismo y del apocalipsis, considerado como inminente para esos profetas (hombres entre 50 y 60 años) que dejaban a sus familias y atravesaban los desiertos de Palestina diciendo cosas parecidas a las que decía Jesucristo: "Abandonad a vuestras familias y seguidme", Brown desarrolla sobre todo la idea de que absteniéndose de actividad sexual, el cristiano participa de la victoria de Cristo, triunfa

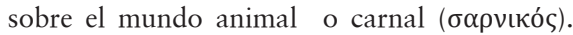
El autor va más lejos: piensa que al final del siglo I, los cristianos «se creyeron obligados a dotarse de un equivalente de la ley judia, si querían sobrevivir como un grupo identificable, distinto de los paganos y los judios». Ese signo distintivo era la abstinencia: "Por encima del conglomerado sólido de las antiguas nociones judías -dice- se elevaba el pico de la absoluta castidad». Y una de las razones por las cuales Eloísa se niega a casarse con Abelardo está en que lo quiere salvar de la indignidad, ya que para un teólogo notorio, «el matrimonio era una vocación sin gloria».

4. Foucault Michel (2001), "Sexualité et solitude" en Dits et écrits, Paris, Gallimard, Tome I, pp. 168-178.

5. Objeto de múltiples análisis, el uso de etiam es un recurso retórico crucial en muchas fórmulas agustinianas. Es adoptado por Paul
Claudel en el epígrafe de la obra teatral Tête d'Or: etiam peccata (también por los pecados ... nos salvamos).

6. "Desde el descubrimiento del complejo de Edipo hasta Moisés y el monotéismo, pasando por la extraordinaria paradoja desde el punto de vista científico de Tótem y Tabú, Freud no se planteó, personalmente, más que una sola pregunta: ¿Cómo ese sistema significante sin el cual no hay ninguna encarnación posible ni de verdad ni de justicia, cómo ese logos literal puede incidir en un animal ajeno a ese sistema y al que no le importa de él, porque eso no interesa en lo más mínimo a sus necesidades? Sin embargo, es eso lo que provoca el sufrimiento neurótico." (la traducción es mía)

7. Remito al capítulo "Paréntesis sartreano" en Sara Vassallo (2015), El deseo y la gracia, Nube Negra, Rosario.

REFERENCIAS BIBLIOGRÁFICAS

Abélard-Héloise (1938, Vrin), Correspondance Héloïse-Abélard, Préface de Étienne Gilson, Folio-Classique, 2000,Paris, Gallimard.

Agustín (san) de Hipona, (1960) Cité de Dieu, ed. Desclée de Brouwer, Bibliothèque Augustinienne, Paris. (1948), Tratado de la Trinidad, Madrid, BAC. (1964) Les Confessions, Paris, Garnier. (1981) Mélanges doctrinaux, vol. 12 en Oeuves Complétes, Paris, Desclée De Brouwer.

AlexAndRe, Jerôme (2001), Une chair pour la gloire, Paris, Beauchesne.

Baudelaire, Charles (2002), Les Fleurs du Mal, poème 42, Paris, GarnierFlammarion. 
Bible (LA) (1993), Association Viens et Vois, Grezieu la Varenne.

De Lubac, Henri (2009), Corpus mysticum, l'Eucharistie et l'Église au Moyen âge, Étude historique, Paris, ed. Du Cerf (sobre todo el capítulo "Caro spiritualis").

De Certeau, Michel (1982) La Fable mystique I, XVIe et XVIIe siècles, Paris, Gallimard.

Gilson, Étienne (1999), Saint-Augustin. Philosophie et incarnation, Paris, Ad Solem.

Henry, Michel (1987), Incarnation. Une philosophie de la chair, Paris, Seuil. Irénée de Lyon (1969), Contre les hérésies, Paris, ed. du Cerf.

Juan (san), evangelio de, en Bible (la) (1993), Association Viens et Vois, Grezieu la Varenne.

KierkegaArd, Soren (2011) Las obras del amor y otros textos, Bs As, Leviatán (introducción y traducción de Sara Vassallo).

LACAN, Jacques (1981) Libro III del Seminario (Les Psychoses), Paris, Seuil; (1972-1973) Libro XIX del Seminario (Ou pire...), versión dactilográfica en francés; (1973-1974) Libro XXI del Seminario (Les nondupes errent, versión dactilográfica en francés); (1974-1975) Libro XXII del Seminario (RSI, en revista ORNICAR, $\mathrm{n}^{\circ} 2$ y siguientes); (1966) «Subversion du sujet et dialectique du désir» (Écrits II), Paris, Points-Seuil [la traducción es mía]; (1966) «L'instance de la lettre dans l'inconscient» en Écrits I, PointsSeuil [la traducción es mía].

Lacoste, Jean-Yves (1998), Dictionnaire critique de théologie, Paris, PUFQuadrige.

Mateo (evangelio según), en Bible (LA)
(1993), Association Viens et Vois, Grezieu la Varenne.

Pablo (san), Epístola a los Corintios, Epístola a los Romanos, Epístola a los Colosenses, Epístola a los Filipenses en Bible (LA) (1993), Association Viens et Vois, Grezieu la Varenne.

Tertuliano (1990-2004) Contre Marcion, Paris, ed. Le Cerf. (2001) Acerca del alma, Madrid, ed. Akal. (1980) La résurrection des morts, Paris, Desclée De Brouwer. (2010) Encycl. Universalis, Tertullien, La Résurrection des morts (http://catalogue.bnf.fr/ ark:/12148/cb165508828).

Sartre, Jean Paul (1964), Les mots, Paris, Gallimard.

Vassallo, Sara (2015), El deseo y la gracia, Rosario, Nube Negra.

\section{RESEÑA CURRICULAR DEL AUTOR}

Sara Vassallo es Licenciada en Letras, UBA y Doctora en Letras por la Universidad de Aix-Marsella. Docente UBA y UNR. 